\title{
Pseudarthrosis - A pictorial essay
}

\author{
Subbarao Kakarla ${ }^{1, *}$
}

${ }^{1}$ KIMS Foundation and Research Centre, Minister Road, Secunderabad - 500003, Telangana, India

\begin{abstract}
Pseudoarthrosis rarely presents as a diagnostic problem. However, since there are several etiologies, the specific cause may be difficult to identify. Radiologically, five morphological forms exist, although there is some overlap of these. The major form is hypertrophic and the other one is atrophic. The radiological characteristics are described illustratively. Often the etiological factors reflect on radiological presentation. Pseudo joint formation also occurs at transitional vertebrae of the lumbosacral spine, between spinous processes of L4-L5 and in late stages of congenital dislocations of hip.
\end{abstract}

Keywords: Pseudoarthrosis; etiology; radiographic findings; Pseudo joint; extremities; spine

*Corresponding author: Prof. Kakarla Subbarao, MS, D.Sc. (HON), FRCR, FACR, FICP, FSASMA, FCCP, FICR, FCGP, Chairman, KIMS Foundation and Research Centre, Minister Road, Secunderabad 500003, Telangana, India. Email: subbaraokakarla25@gmail.com

Received 19 October 2019; Revised 28 November 2019; Accepted 05 December 2019; Published 18 December 2019

Citation: Kakarla S. Pseudarthrosis - A pictorial essay. J Med Sci Res. 2020; 8(1):17-24. DOI: http://dx.doi.org/10.17727/ JMSR.2020/8-3

Copyright: (C) 2020 Kakarla S. Published by KIMS Foundation and Research Center. This is an open-access article distributed under the terms of the Creative Commons Attribution License, which permits unrestricted use, distribution, and reproduction in any medium, provided the original author and source are credited.

\section{Introduction}

Pseudoarthrosis is generally defined as a joint formation due to failure of bony union between two segments of a tubular bone away from the joints. It is an abnormal union formed by fibrous tissue between parts of a bone that has fractured. It can be spontaneous due to congenital weakness. The clinical presentation of pseudoarthrosis most often includes pain, swelling and false movement.

Table 1: Various etiological factors.

\begin{tabular}{|ll|}
\hline - & Congenital/ Idiopathic \\
- & Osteogenesis imperfecta \\
- & Neurofibromatosis \\
- & Osst traumatic \\
- & Fractures in syringomyelia and meningocele \\
- & Ankylosing spondylitis \\
- & Endiation induced fracture inflammatory arthritides \\
- & Transitional vertebra at lumbosacral junction - \\
& Bertolotti's syndrome \\
\hline
\end{tabular}


Prevention of pseudoarthrosis can be difficult. Part of the difficulty of prevention may be the risk factors of the patient that are often non-modifiable in the short term. Table 1 gives the various etiological factors which can cause pseudoarthrosis and pseudo joint formation.

\section{Imaging findings and review of the literature}

Conventional radiology is adequate most of the times. Rarely the other newer modalities are adopted, particularly when complications occur.

Pseudoarthrosis usually follows a fracture, whether traumatic or otherwise, with no attempt at repair. Non union is permanent failure of healing following a broken bone unless intervention (such as surgery) is performed. A fracture with non union generally forms a structural resemblance to a fibrous joint, and is therefore often called a "false joint" or pseudoarthrosis (the Greek term "pseudo-" means false and "arthrosis" means joint).

The causes for non-union include: avascular necrosis, abnormal alignment of the fractured fragments, infection, particularly osteomyelitis, immobilisation and soft tissue interposition between the two fragments.

It occurs in both adults and children. The tibia and fibula, usually the lower parts are most commonly affected. Less often the upper third of the femur, the upper and middle thirds of the clavicle and humerus and the lower part of the forearm are involved [1].

\section{Congenital $[1,2]$}

Congenital pseudoarthrosis of the tibia is the most common entity in children. The etiology cannot always be established. Congenital pseudoarthrosis is usually apparent shortly after birth and is rarely diagnosed after the age of two. About $50 \%$ of cases are associated with neurofibromatosis type 1 (NF1). Overall, $10 \%$ of patients with NF1 are diagnosed with tibial pseudoarthrosis. Fibular, ulnar, and radial pseudoarthrosis can also occur, but much less frequently, and usually only in patients with NF1. Radiological features include: progressive bowing, resorption of a short segment of bone and angulation at the site of resorbed bone.
It is likely to be a primary periosteal disease and secondary bone disease. The pathobiology demonstrates increased osteoclasis by the surrounding fibrous hamartoma and reduced osteogenesis and morphogenic protein production by the bone. This leads to a loss of remodelling potential and gradual bowing and atrophy of the bone with eventual fracture of the tibia and/or fibula (Figure 1).

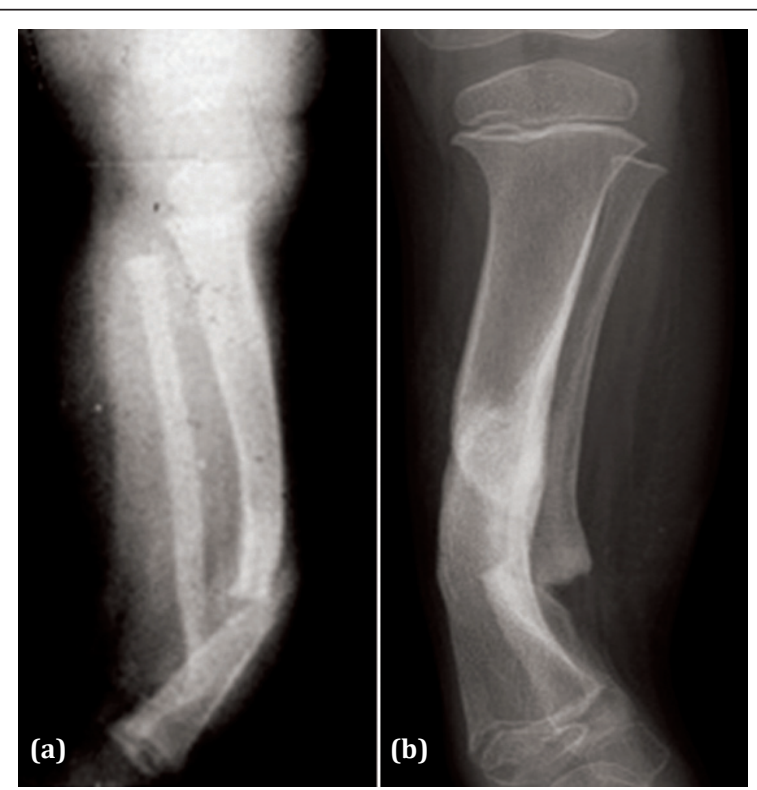

Figure 1a, b: Pseudoarthrosis, congenital, idiopathic.

\section{Osteogenesis imperfecta [3]}

It is a non sclerosing skeletal dysplasia and constitutes four forms. Fragility of bones, thinning of the bones, bidding of the bones and fractures are common (Figure 2). Pseudoarthrosis occurs when the fractures do not heal properly.

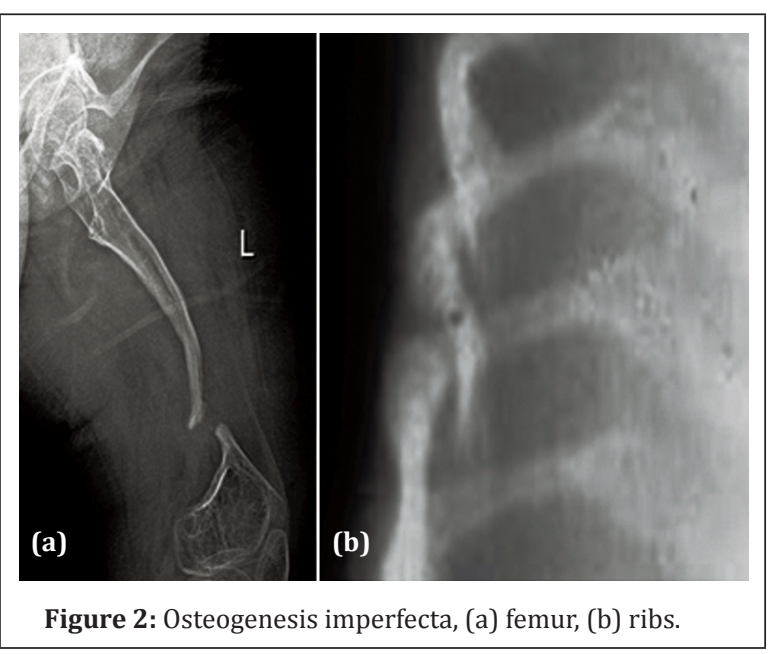




\section{Fibrous dysplasia [4-6]}

It is a mixed skeletal dysplasia where both lytic and sclerotic changes occur due to aberrant fibrous tissue formation in skeleton. It can be monostotic, polyostotic and McCune-Albright Syndrome (MAS). Pseudoarthrosis is occasionally encountered in polyostotic fibrous dysplasia and MAS (Figure 3).

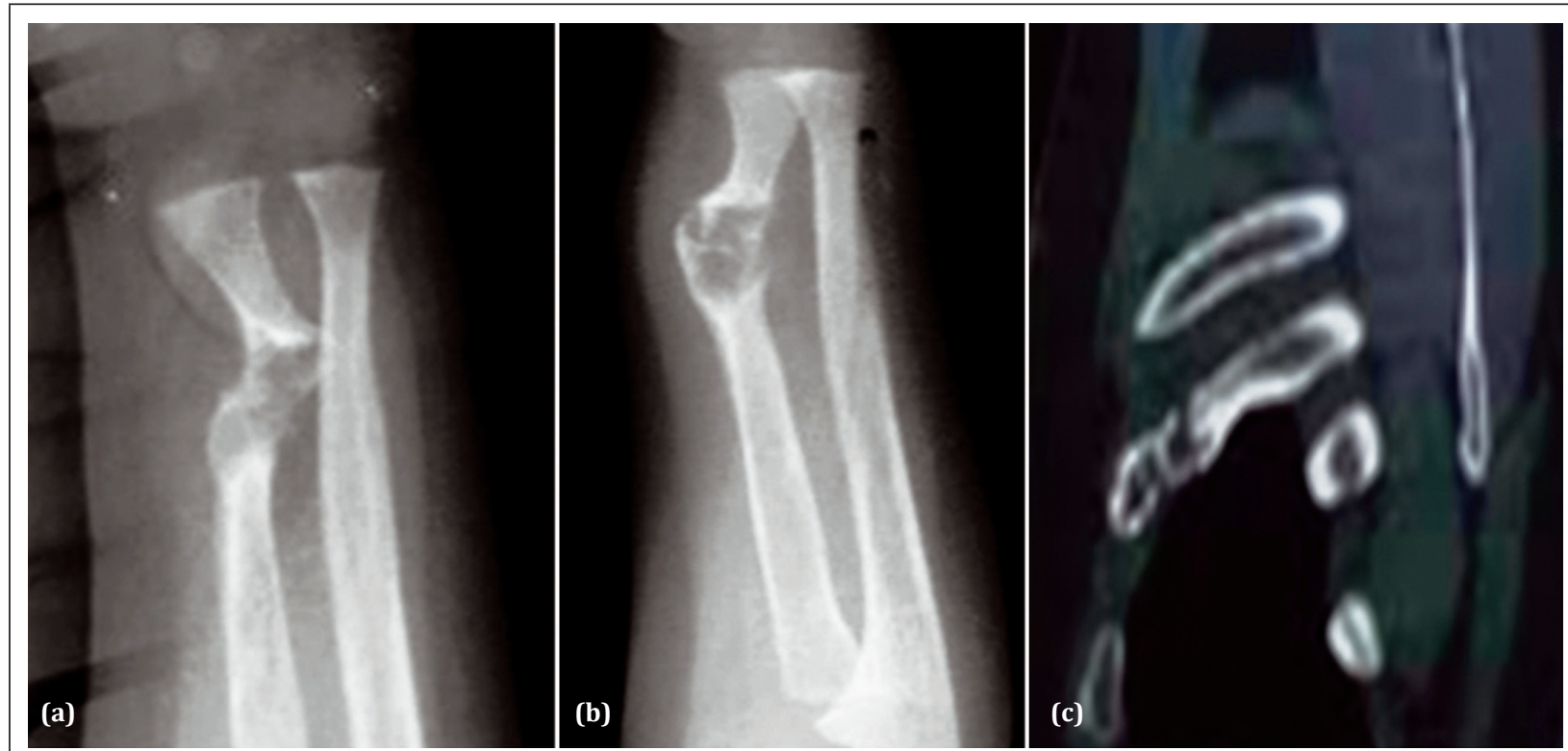

Figure 3a-c: Pseudoarthrosis of the radius in fibrous dysplasia.

\section{Neurofibromatosis $[7,8]$}

Neurofibromatosis (NF1) is an inherited disorder transmitted as an $\mathrm{AD}$, with variable gene expression (Figures 4, 5 and 6). NF1 (von recklinghausens, café au lait spots, neurofibromas, bone changes), it is a neuroectodermal \& mesodermal dysplasia. Pseudoarthrosis occurs due to mesenchymal dysplasia of the bones resulting in fractures. Actual neurofibromata may not be seen at the site of fractures. Evolution of pseudoarthrosis in NF1 is as follows: $10 \%$ of neurofibromatosis patients develop pseudoarthrosis with tendency to develop in the distal half of tibia. $50 \%$ of congenital pseudoarthrosis are due to neurofibromatosis.

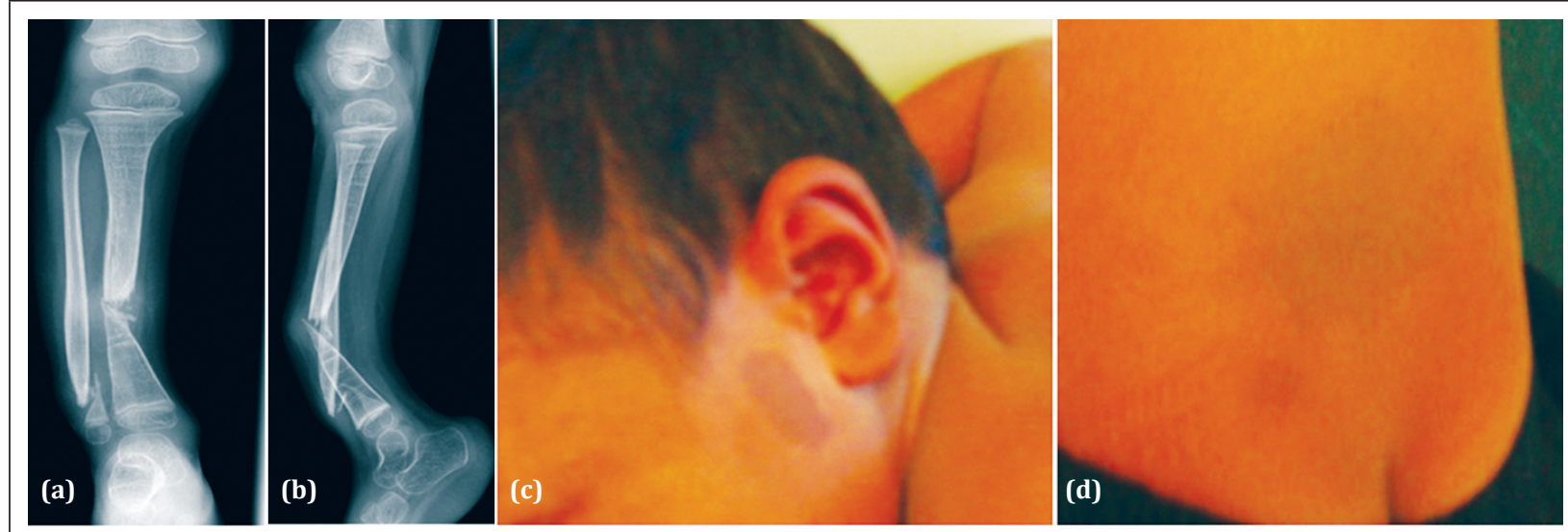

Figure 4a-d: Pseudoarthrosis of tibia and fibula - NF1.

\section{Traumatic [9-12]}

Disturbed fracture healing- normal fracture healing can be disrupted in numerous ways (Figure 7):
Pseudoarthrosis (Non-union), fracture healing does not occur within 6-9 months. 


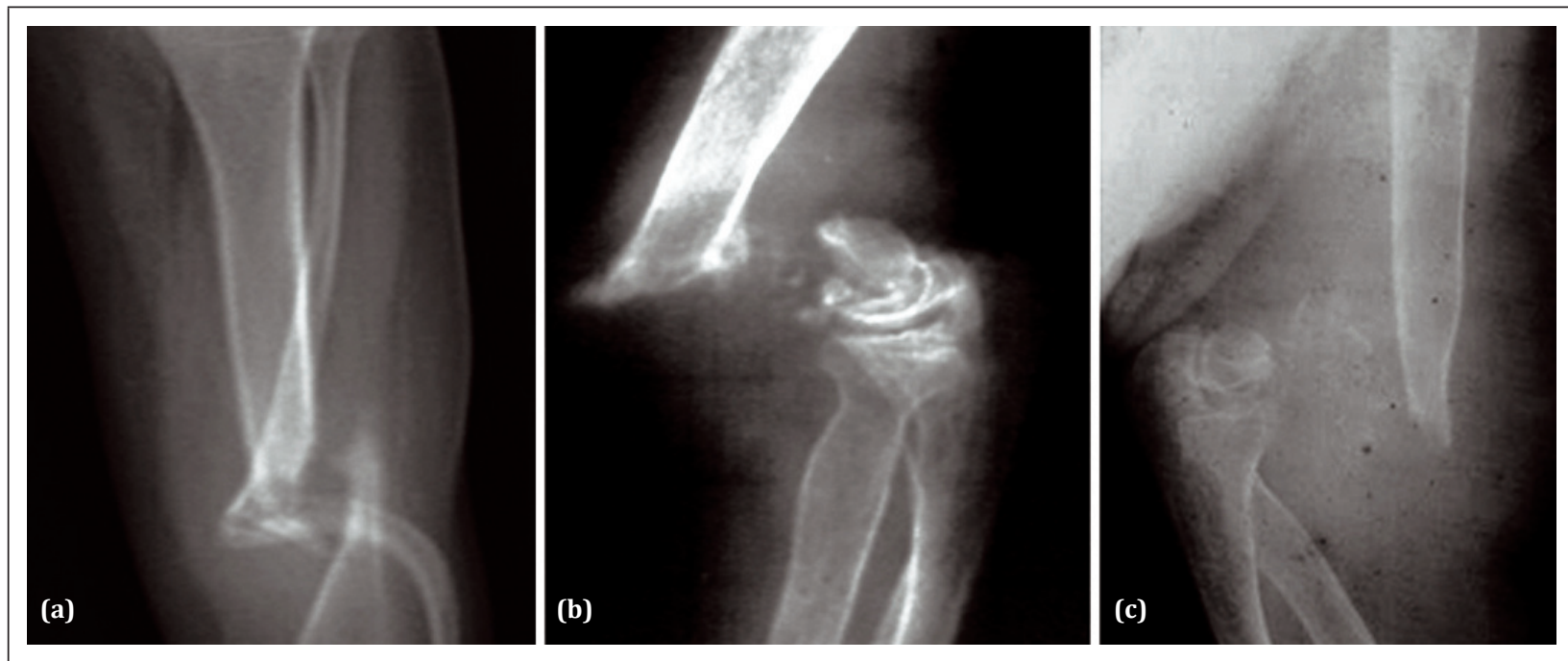

Figure 5: Pseudoarthrosis (a) tibia (NF1), (b and c) NF1 pseudoarthrosis of humerus- hypertrophic and atrophic.
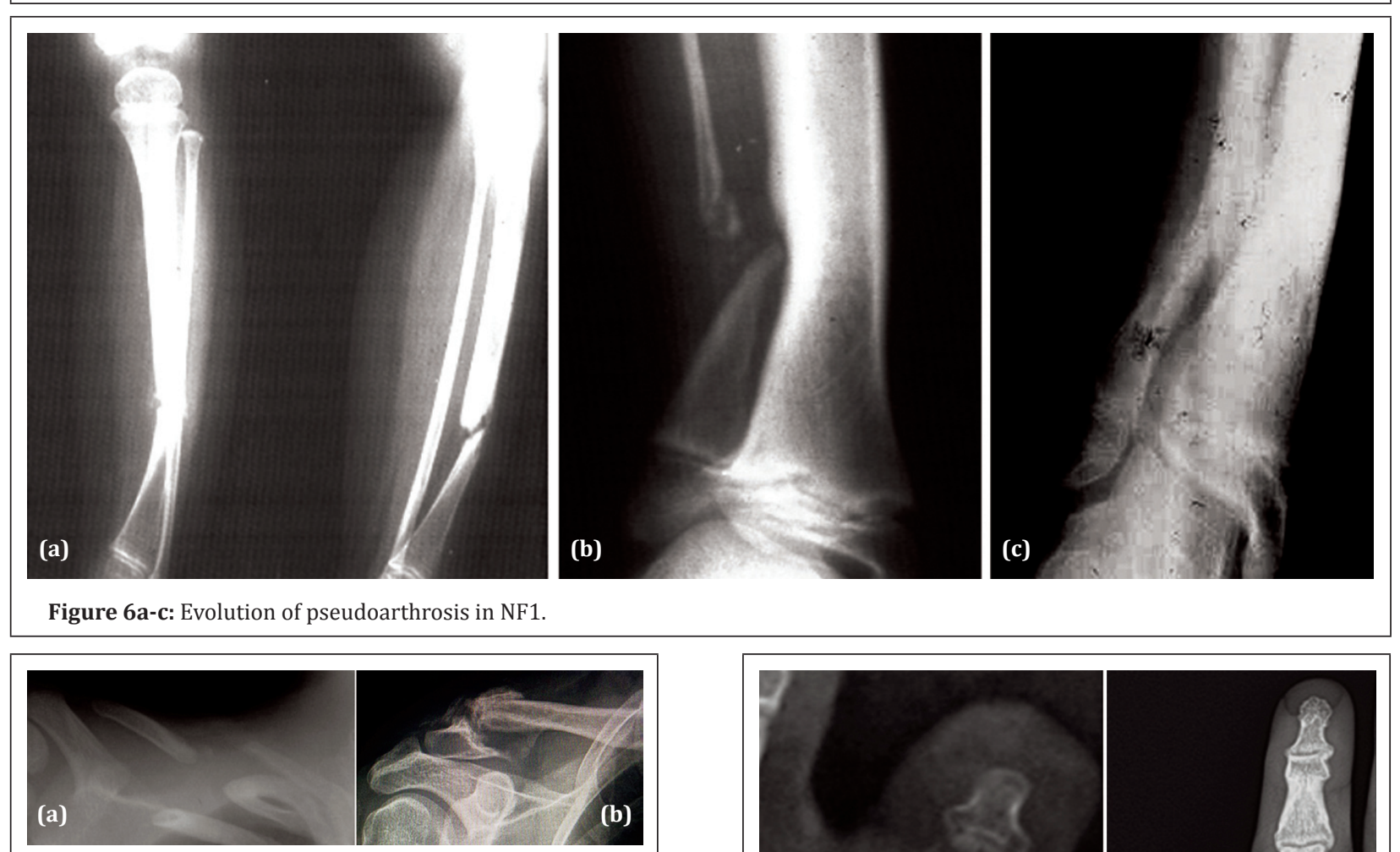

Figure 7a, b: Pseudoarthrosis of the clavicle - non-union of the fractures.
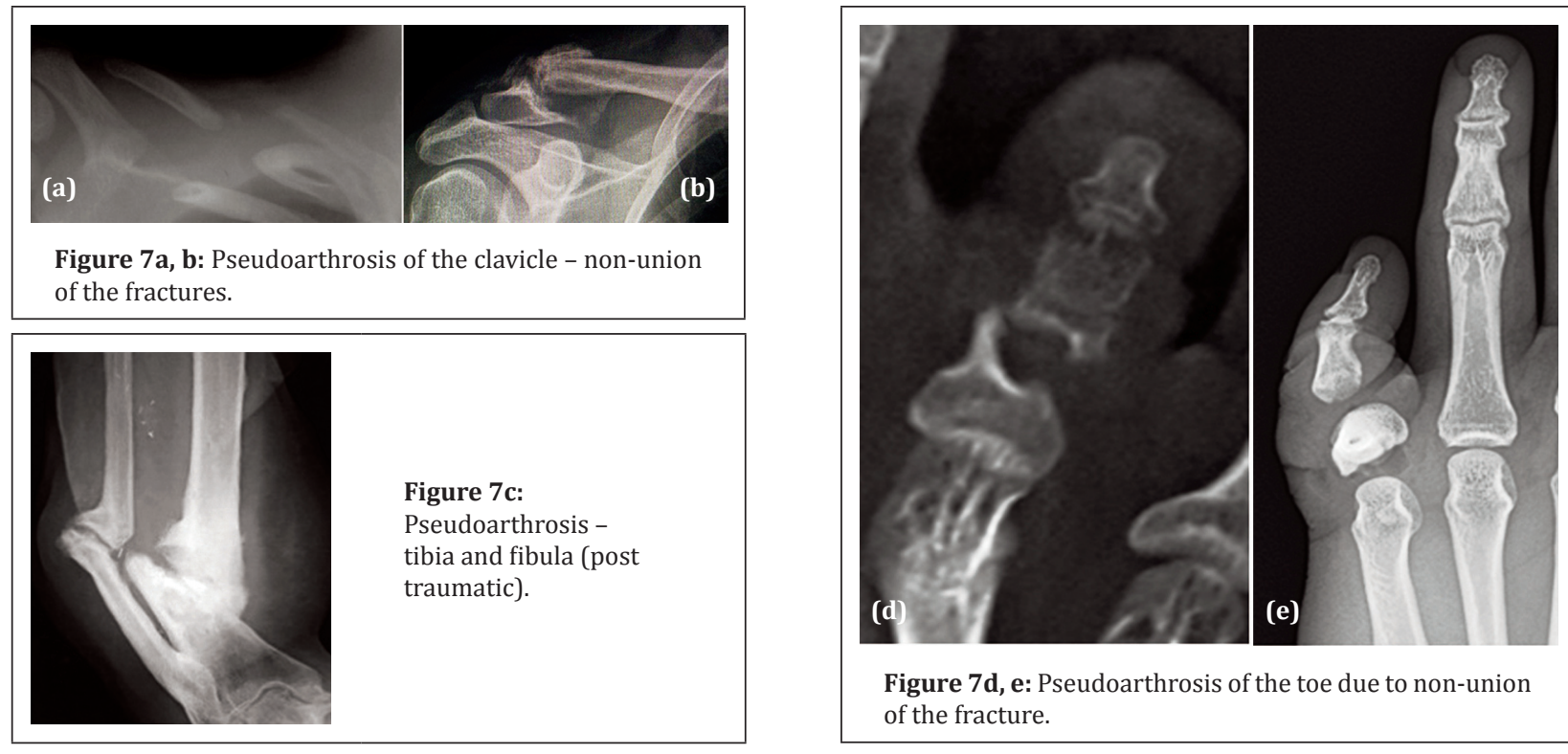

Figure 7d, e: Pseudoarthrosis of the toe due to non-union of the fracture. 

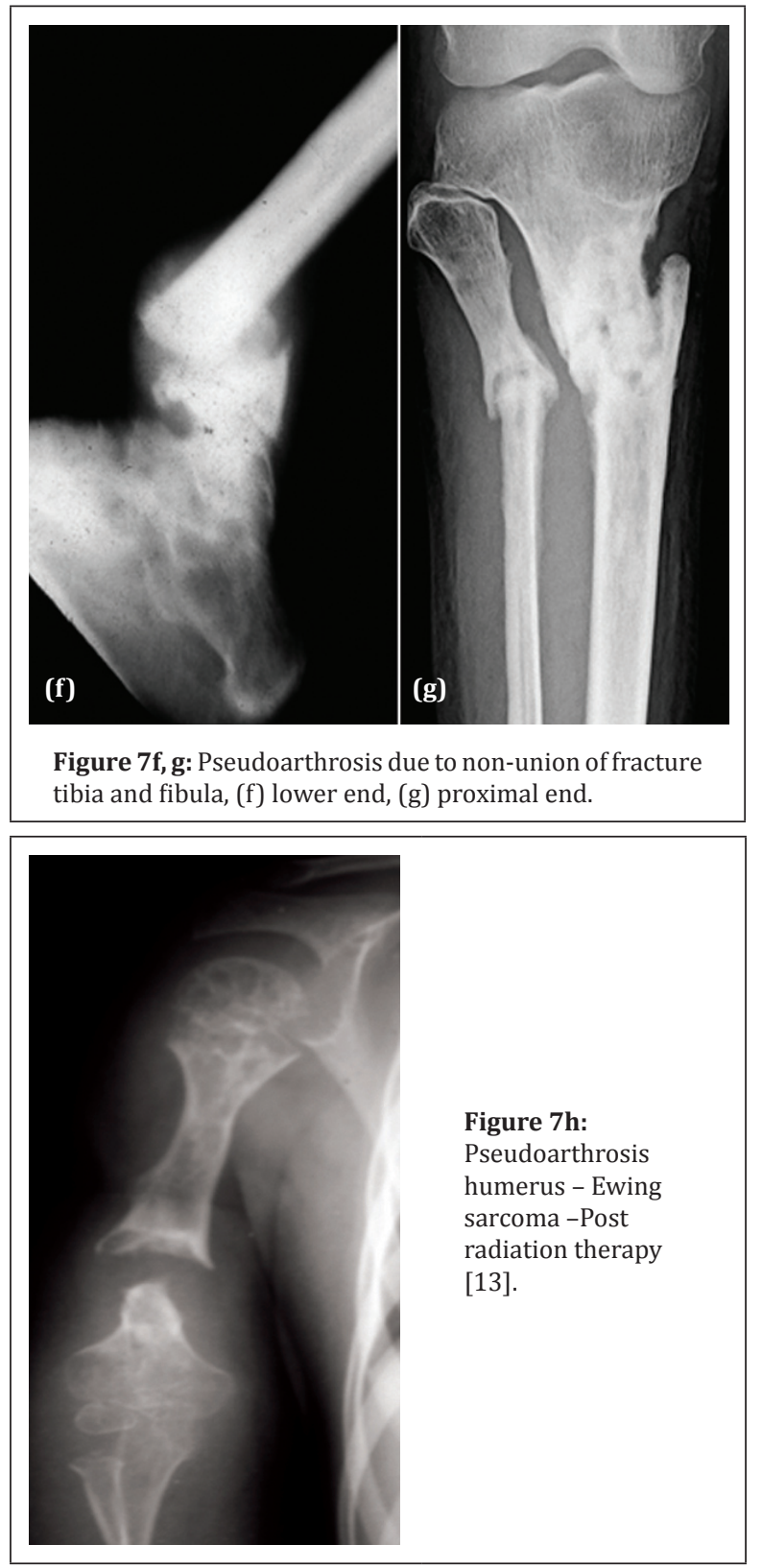

\section{Causes related to fracture}

- $\quad$ Related to the fracture site.

- Soft tissue interposition.

- Bone loss at the fracture.

- Infection.

- Loss of blood supply.

- Damage of surrounding muscles.

\section{Types of pseudoarthrosis}

1. Hypertrophic pseudoarthrosis

- rich in callus (elephant foot)

- $\quad$ poor in callus (horse hoof)
2. Oligotrophic pseudoarthrosis

- no callus on radiographs, rounded fracture ends

3. Atrophic pseudoarthrosis

- bone resorption due to infection or impaired blood supply

4. Hypotrophic (non-vital) pseudoarthrosis

- necrotic fragments (increasing fragment density without callus formation)

5. Defect pseudoarthrosis

- $\quad$ missing fragments

\section{Crawford's classification of pseudoarthrosis (Figure 8) [14]}

1. Type I - anterolateral bowing with medullary sclerosis.

2. Type II - "failure of tubulation," with constriction or narrowing of the cortical diameter.

3. Type III - a cystic lesion.

4. Type IV - frank pseudoarthrosis with tapered bone ends.

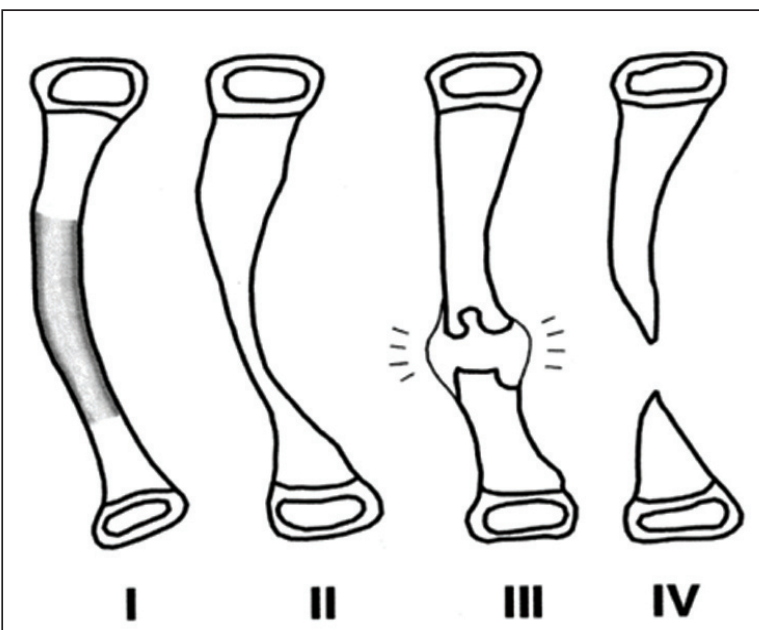

Figure 8: Crawford's classification of pseudoarthrosis.

\section{Osteofibrous dysplasia [5, 6]}

The association between congenital pseudoarthrosis and osteofibrous dysplasia of the tibia and fibula is a rare entity that has been recently recognized. Histopathological examination confirmed the diagnosis of congenital pseudoarthrosis of the tibia and fibula with underlying osteofibrous dysplasia involving both bones (Figure 9). Immunohistochemical stains showed cytokeratin positivity. 

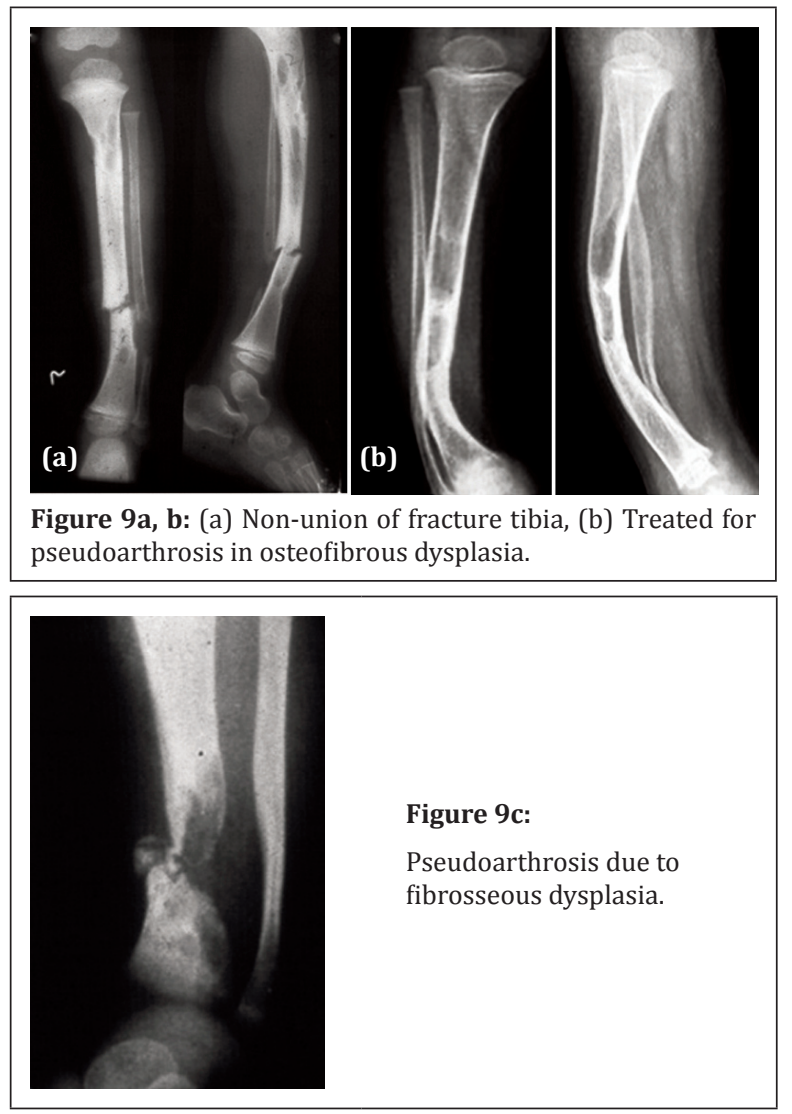

\section{Infections (Figure 10)}
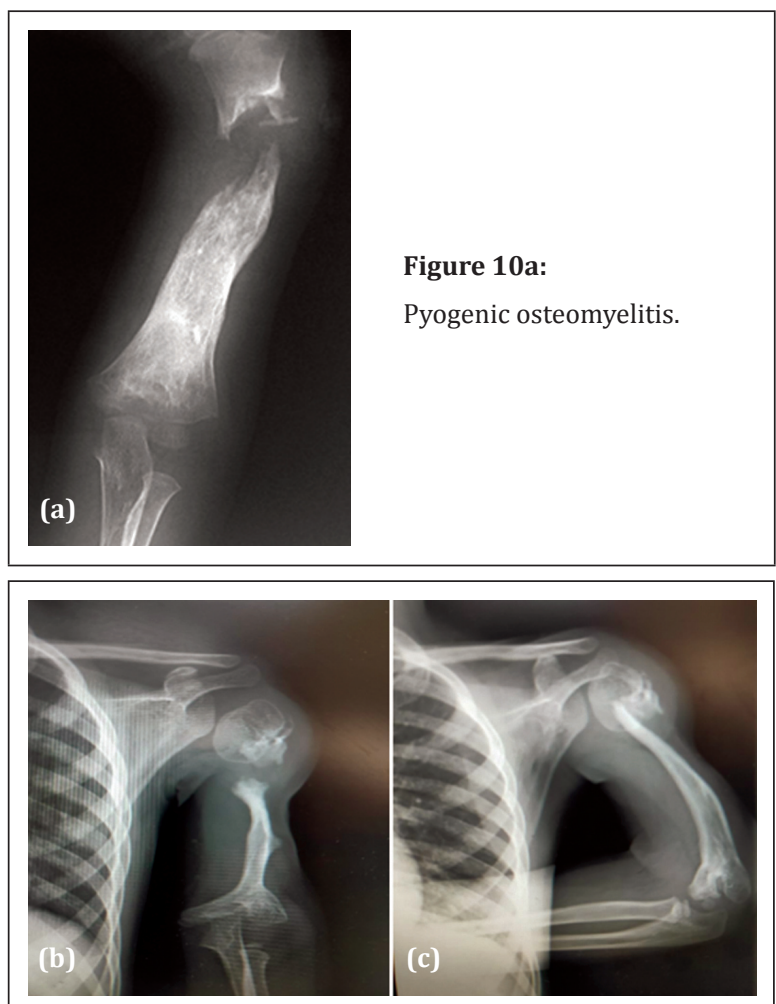

Figure 10b, c: Chronic osteomyelitis.

\section{Neuropathic (Figure 11)}

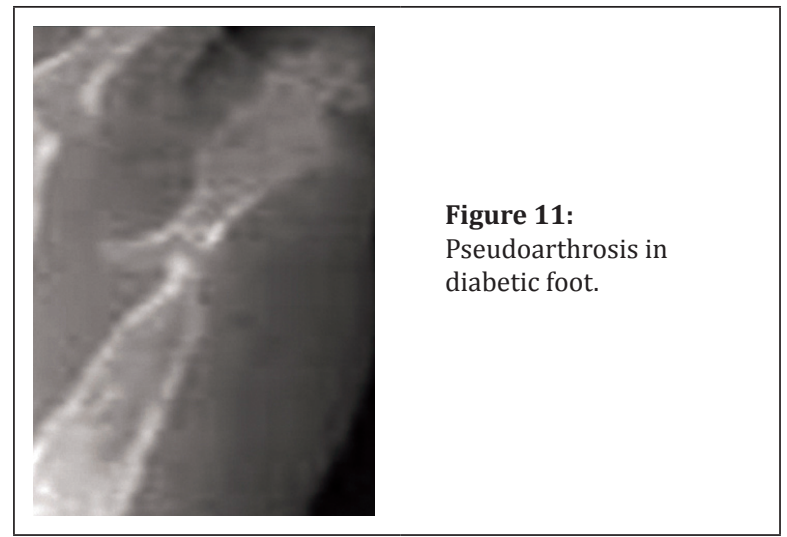

\section{Trauma (Figure 12)}

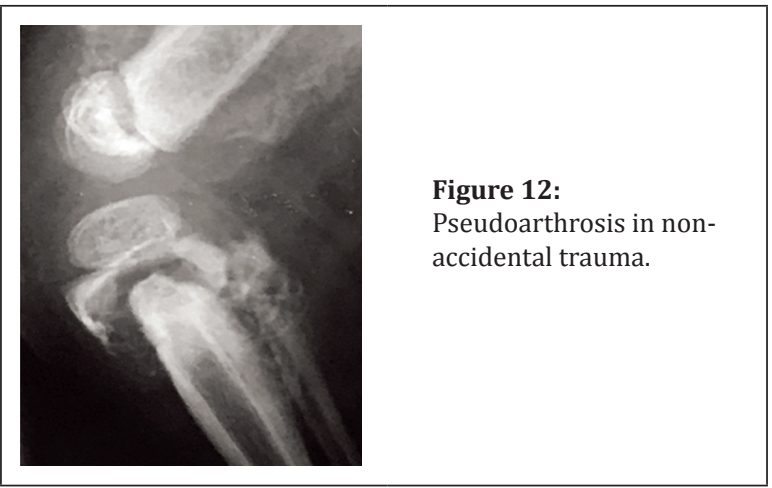

\section{Bertolotti syndrome $[15,16]$}

A false joint may be formed at the lumbo sacral junction with transitional vertebrae. The transverse process of L5 articulates with the ala of the sacrum and forms a joint. It could be unilateral or bilateral (Figure 13). Bertolotti syndrome is where the young patient complains of back pain with transitional vertebrae and is characterised by the presence of a fifth lumbar (L5) vertebra anatomic variation with a large transverse process that forms a pseudoarthrosis or a bony fusion with the sacrum or iliac crest.

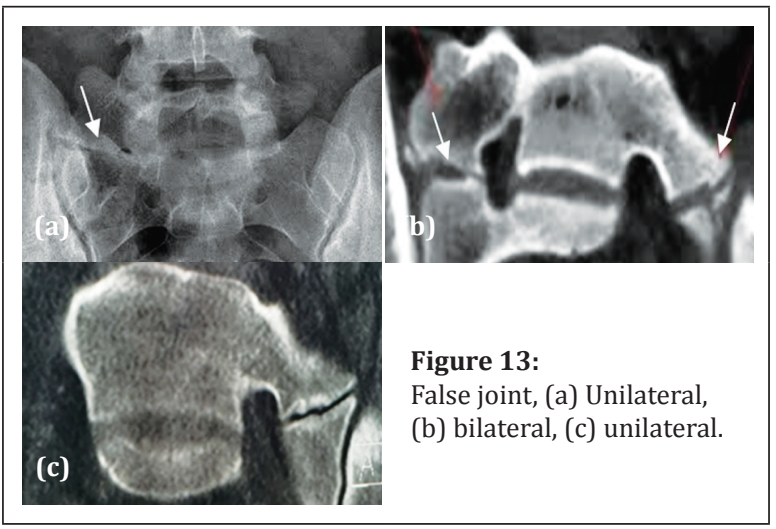




\section{Ankylosing spondylitis [17, 18]}

A well-known complication in patients with ankylosing spondylitis (AS) is the development of localised vertebral or discovertebral lesions of the spine (Figure 14). This was first described by Andersson in 1937. Since then, many different terms are used in literature to refer to these localised lesions of the spine, including the eponym 'Andersson lesion' (AL). The use of different terms reflects an ongoing debate on the exact aetiology of the AL. AL may result from inflammation or stress fractures of the complete ankylosed spine. There is no evidence for an infectious origin. Regardless of the exact aetiology, a final common pathway exists, in which mechanical stresses prevent the lesion from fusion and provoke the development of pseudoarthrosis. The diagnosis of AL is established on conventional radiography, but computed tomography and magnetic resonance imaging both provide additional information.

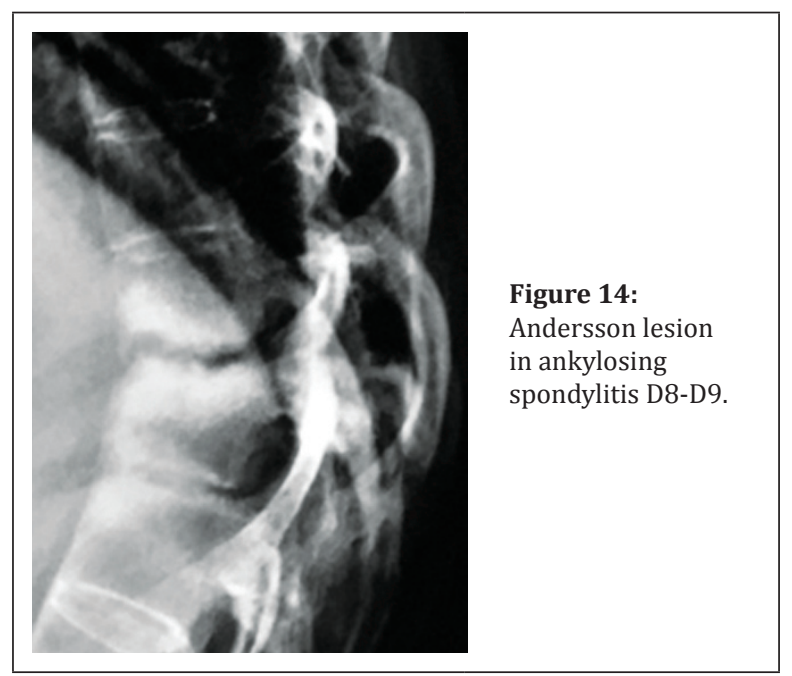

\section{Baastrup disease [19]}

Chronic contact between spinous processes may induce osseous hypertrophy and eburnation at this pathological joint, generally at L4-L5 (Figure 15).

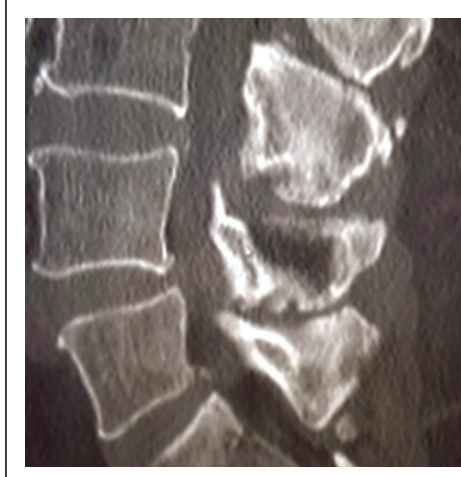

Figure 15a:

Baastrup disease L4-L5 spinous processes.

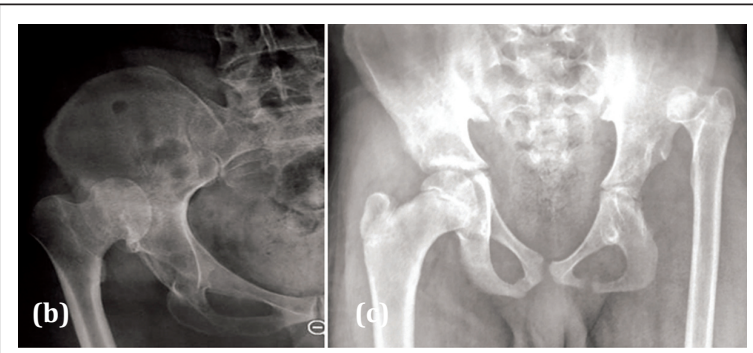

Figure 15b, c: Pseudo joint formation in neglected acetabular dysplasia [20].

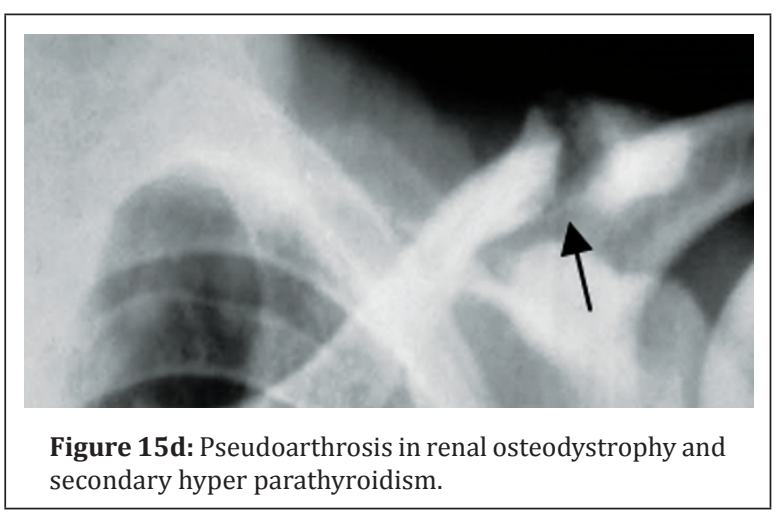

\section{Conclusion}

Pseudoarthrosis is often encountered radiologically. The etiological factors are many and varied, but the radiological manifestations are few and some of them are common to all. The imaging findings of pseudoarthrosis have been described in different disorders. Conventional radiology is adequate in identifying the disorder.

\section{Acknowledgements}

NIMS, KIMS, KREST Museum Hyderabad, India.

\section{Conflicts of interest}

Author declares no conflicts of interest.

\section{References}

[1] Paley D. Congenital pseudarthrosis of the tibia: biological and biomechanical considerations to achieve union and prevent refracture. J Child Orthop. 2019; 13(2):120-133.

[2] Sharma R, Dixon A. Congenital pseudoarthrosis of the tibia. Radiopaedia. Available from: https://radiopaedia.org/ articles/congenital-pseudoarthrosis-of-the-tibia

[3] Jin TY, Farooq S. Osteogenesis imperfecta. Radiopaedia. Available from: https://radiopaedia.org/articles/ osteogenesis-imperfecta-1

[4] Uwaifo GI, Sarlis NJ, Scheinfeld NS. What are the possible complications of polyostotic fibrous dysplasia (PFD) in McCune-Albright syndrome (MAS)? MedScape. 2019; Available from: https://www.medscape.com/ answers/127233-155905/what-are-the-possiblecomplications-of-polyostotic-fibrous-dysplasia-pfd-inmccune-albright-syndrome-mas 
[5] Teo HEL, Peh WCG, Akhilesh M, Tan SB, Ishida T. Congenital osteofibrous dysplasia associated with pseudoarthrosis of the tibia and fibula. Skeletal Radiol. 2007; 36(Suppl 1):S714.

[6] Weerakkody Y, Kulkarni K. Osteofibrous dysplasia. Radiopaedia. Available from: https://radiopaedia.org/ articles/osteofibrous-dysplasia-2?lang=us

[7] Aegerter EE. the possible relationship of neurofibromatosis, congenital pseudarthrosis, and fibrous dysplasia. J Bone Joint Surg Am. 1950; 32-A(3):618-626.

[8] Kaur S, Thami GP, Kanwar AJ. Pseudoarthrosis in neurofibromatosis type-1. Postgrad Med J. 2001; 77(912): 660.

[9] Franco MJO. Fracture non union and pseudoarthrosis. Radiopaedia. Available from: https://radiopaedia.org/ cases/fracture-non-union-and-pseudoarthrosis

[10] Gillard JH, Jager HR. Grainger \& Allison's Diagnostic Radiology: The Spine. Elsevier Health Sciences, 2015.

[11] Knipe H, Schubert R. Fracture healing. Radiopaedia. Available from: https://radiopaedia.org/articles/fracture-healing

[12] Isidoro B. Pseudarthrosis of the long bones. The Journal of Bone and Joint Surgery. 1947; 29(1):97-106.

[13] Mitchell MJ, Logan PM. Radiation-induced changes in bone. Radiographics. 1998; 18(5):1125-1136.

[14] Pannier S. Congenital pseudarthrosis of the tibia. Orthop Traumatol Surg Res. 2011; 97(7):750-761.

[15] Neelakantan S, Anandarajan R, Shyam K, Philip B. Multimodality imaging in bertolotti's syndrome: An important cause of low back pain in young adults. BMJ Case Rep. 2016; 2016:bcr2016217121.

[16] Muniraj S. Bertolotti syndrome (lumbosacral transitional vertebrae). Radiopaedia. Available from: https:// radiopaedia.org/cases/bertolotti-syndrome-lumbosacraltransitional-vertebrae?lang=us

[17] Bron JL, Vries MKD, Snieders MN, Horst IEVD-Bruinsma, Barend J van Royen. Discovertebral (Andersson) lesions of the spine in ankylosing spondylitis revisited. Clin Rheumatol. 2009; 28(8):883-892.

[18] Chan FL, Ho EK, Chau EM. Spinal pseudoarthrosis complicating ankylosing spondylitis: Comparison of CT and conventional tomography. AJR Am J Roentgenol. 1988; 150(3):611-614.

[19] Weerakkody Y, Gaillard F. Baastrup syndrome. Radiopaedia. Available from: https://radiopaedia.org/articles/baastrupsyndrome

[20] Norris CM. Chapter 8 - The hip and thigh. Managing Sports Injuries (Fourth Edition) 2011; pp.143-164. 